Е.П. МЕРКУЛОВА ${ }^{1}$, Д.М.Н., профессор, С.Н. КОЛЕСНИКОВА ${ }^{2}$

${ }^{1}$ Белорусская медицинская академия последипломного образования, Минск

2 Гомельская областная клиническая больница, Республика Беларусь

\title{
ХРОНИЧЕСКАЯ
}

\section{НАЗАЛЬНАЯ ГИПЕРРЕАКТИВНОСТЬ}

\section{(СОВРЕМЕННЫЕ КЛАССИФИКАЦИИ, КЛИНИЧЕСКАЯ КАРТИНА, ДИАГНОСТИКА)}

\begin{abstract}
Назальная гиперреактивность (НГ) - это клинический феномен, проявляющийся повышенной индивидуальной чувствительностью слизистой полости носа к факторам, которые не вызывают симптомов у здоровых людей.

Понятие назальной гиперреактивности принято в мировой литературе и включает в себя повышенную реактивность слизистой оболочки носа, вызванную различными физическими, химическими или фармакологическими раздражителями [1, 2]. У $86 \%$ детей с бронхиальной астмой выявляется назальная гиперреактивность.
\end{abstract}

Ключевые слова: назальная гиперреактивность, классификация, симптоматика, диагностика, лечение.

E.P. MERKULOVA ${ }^{1}$, MD, Prof., S.N. KOLESNIKOVA ${ }^{2}$

${ }^{1}$ Belarusian Medical Academy of Postgraduate Education, Minsk

2 Gomel' Regional Clinical Hospital, Belarus

CHRONIC NASAL HYPER-REACTIVITY (CURRENT CLASSIFICATIONS, CLINICAL PATTERN, DIAGNOSIS)

Nasal hyper-reactivity (NG) is a clinical phenomenon manifested by increased individual sensitivity of the nasal mucosa to factors that do not cause symptoms in healthy people.

The concept of nasal hyperreactivity is accepted in the world literature and implies increased reactivity of the nasal mucosa caused by various physical, chemical or pharmacological stimuli [1, 2]. Nasal hyper-reactivity is found in $86 \%$ of children with bronchial asthma.

Keywords: nasal hyper-reactivity, classification, symptoms, diagnosis, treatment.

B Европе данные о распространенности аллергического ринита колеблются от 5 до 27\%. Считают, что гиперреактивные формы ринита неаллергического генеза отмечаются у 15\% населения [3].

Генез НГ: вирусы, бактерии, грибы, простейшие; химические или физические факторы; эндокринные нарушения, беременность, прием гормональных средств, в том числе противозачаточных; загрязнение окружающей среды; вторичный ринит в результате аденоидов, гипертрофии нижних носовых раковин, полипов, опухоли полости носа или носоглотки.

Классификация НГ представлена в таблице 1.

Для обозначения понятия НГ в разных странах мира используют самые разнообразные термины. Понятие «ринит» подразумевает воспаление, термин «ринопатия» является более широким и включает в себя аутоиммунные нарушения и опухолевые процессы.

В англоязычной литературе принят термин «NINA»: Не Инфекционный, Не Аллергический ринит. В немецкоговорящих странах более распространен термин «вазомоторный ринит», который включает в себя васкулярный компонент в патогенезе заболевания, а также вазомоторный компонент при аллергической реакции.

Основные механизмы развития НГ:

- специфическая гиперреактивность слизистой оболочки полости носа - аллергическое воспаление [4; 5]; неспецифическая гиперреактивность слизистой оболочки полости носа:

- воздействие вирусов;

- анатомические особенности (гребень перегородки носа с контактом нижней носовой раковины) [6], такой генез заболевания нередко встречается у подростков; - повышение активности тучных клеток при нарушении осмолярности (например, воздействие холодного, сухого воздуха);

- влияние нестероидных противовоспалительных средств - блокада циклооксигеназного пути метаболизма арахидоновой кислоты, приводящая к избытку продукции лейкотриенов;

- эндокринные патологии: гипотиреоз, гиперпаратиреоз, болезнь Аддисона, но лидером среди этой патологии является сахарный диабет;

- токсическое воздействие: металлы, растворители, другие химические вещества;

- побочные действия лекарственных препаратов: антигипертонических средств, ацетилсалициловая кислота, противозачаточные средства;

- постинфекционные причины - это одна из основных причин у детей дошкольного возраста;

- ринит с эозинофилией в крови и секрете полости носа (не аллергический ринит - NAR) [7]. В дальнейшем неаллергический ринит с эозинофилией может пере- 


\section{Таблица 1. Кассификация назальной гиперреактивности}

\begin{tabular}{|c|c|}
\hline Группа & Этиологические факторы \\
\hline $\begin{array}{l}\text { Аллергия: } \\
\text { - Сезонная } \\
\text { - Круглогодичная } \\
\text { - Пищевая } \\
\text { - Профессиональная }\end{array}$ & $\begin{array}{l}\text { Пыльца деревьев, злаковых, сорных трав, } \\
\text { домашняя пыль, дерматофагоидные } \\
\text { клещи, эпидермис животных, пищевые } \\
\text { аллергены (белки коровьего молока и } \\
\text { куриных яиц, рыба, соя, фрукты и овощи } \\
\text { красной и оранжевой окраски), грибко- } \\
\text { вые аллергены }\end{array}$ \\
\hline $\begin{array}{l}\text { Побочные действия лекарств: } \\
\text { - Тип А: истинная аллерия } \\
\text { - Тип B: псевдоаллергия }\end{array}$ & $\begin{array}{l}\text { Любой аллерген-гаптен медикаментоз- } \\
\text { ной природы } \\
\text { Ацетилсалициловая кислота } \\
\text { Гипотензивные препараты } \\
\text { Пищевые добавки (глутамат) }\end{array}$ \\
\hline $\begin{array}{l}\text { Нервно-рефлекторная: } \\
\text { - Холинергическая } \\
\text { - Пептидергическая } \\
\text { - Адренергическая }\end{array}$ & $\begin{array}{l}\text { Острые пищевые приправы } \\
\text { Поллютанты (двуокись серы, озон, фор- } \\
\text { мальдегид, хром, никель), пестициды } \\
\text { «Насморк лыжника» } \\
\text { «Насморк атлета» } \\
\text { «Насморк пожилого человека» }\end{array}$ \\
\hline Ирритативно-токсическая & $\begin{array}{l}\text { Передозировка лекарственных средств } \\
\text { Поллютанты } \\
\text { Беременность } \\
\text { Эндокринные заболевания (гипотиреоз, } \\
\text { гиперпаратиреоз, сахарный диабет, } \\
\text { болезнь Аддисона) } \\
\text { Противозачаточные средства }\end{array}$ \\
\hline Постинфекционная & $\begin{array}{l}\text { После перенесенной вирусной и бакте- } \\
\text { риальной инфекции }\end{array}$ \\
\hline Идиопатическая & $\begin{array}{l}\text { Этиопатогенетические механизмы неиз- } \\
\text { вестны }\end{array}$ \\
\hline $\begin{array}{l}\text { Отдельные формы с неясным } \\
\text { механизмом }\end{array}$ & $\begin{array}{l}\text { Назальный мастоцитоз, неаллергический } \\
\text { ринит с эозинофилией }\end{array}$ \\
\hline
\end{tabular}

ходить в полипозный риносинусит, характеризующийся быстрым прогрессированием роста полипов и частыми рецидивами после хирургического лечения;

- идиопатический ринит, некоторые авторы считают, что причина заболевания, как правило, при отсутствии аллергии трудноустанавливаема, поэтому идиопатический ринит превалирует [7].

Необходимо более подробно остановиться на НГ при эндокринных патологиях. В основе патогенеза НГ при эндокринных заболеваниях лежат общие и местные нарушения деятельности вегетативной нервной системы, поскольку они протекают с сегментарными (периферическими) нарушениями и проявляются вторичным синдромом прогрессирующей вегетативной недостаточности. В ее основе лежит висцеральная полинейропатия, обусловленная вовлечением в патологический процесс вегетативных нейронов боковых рогов спинного мозга и вегетативных ядер ствола головного мозга, нейронов ганглиев симпатической цепочки и периферических ганглиев, расположенных вблизи рабочих органов, а также поражение их аксонов, в том числе и блуждающего нерва. По существу, речь идет о соматоневротическом состоянии, при котором основу сегментарных вегетативных нарушений составляют процессы раздражения и/или выпадения периферических вегетативных нейронов. Преобладают парасимпатические реакции, что проявляется увеличением кровотока в капиллярах, отеком их, набуханием слизистой носа и ближайших к ним пазух. Клинически это проявляется ринореей, закладыванием одной половины носа, чиханием, гиперреактивностью на запахи. Внутри общего синдрома вегетативной дисфункции выделяют более конкретные синдромы. При эндокринных заболеваниях назальная гиперреактивность носит вторичный характер и обусловлена висцеральной нейропатией.

Также отдельно стоит выделить неиммунные механизмы назальной гиперреактивности, которые могут быть проявлением дисбаланса вегетативной нервной системы (нейровегетативный ринит, вазомоторный ринит). Известно, что в норме у лиц молодого возраста несколько преобладает тонус симпатической нервной системы, а у лиц пожилого возраста наблюдается физиологическое преобладание парасимпатического отдела вегетативной нервной системы. В случаях ваготонии у лиц молодого возраста, как правило, возникает нарушение носового дыхания, нередко с гиперсекрецией. У пожилых людей симптом так называемой «висячей капли у носа» является проявлением физиологической ваготонии.

Наконец, неиммунные механизмы назальной гиперреактивности могут быть связаны с понижением гистаминопектической активности плазмы, а также с врожденным дефектом фермента гистаминазы. Имеют значения гистаминолибераторы, влияющие на высвобождение гистамина без участия иммунных комплексов:

- цитрусовые, некоторые медикаменты (резерпин), - аспириновая триада (астматическая триада, синдром Видаля), помимо ринологических проявлений назальной гиперреактивности, характеризуется тяжелым течением бронхиальной астмы, непереносимостью аспирина и других нестероидных противовоспалительных препаратов.

Клинически эти симптомы могут появиться неодновременно, с разницей от нескольких месяцев до нескольких лет. Повышенная чувствительность к аспирину не является результатом иммунной реакции, что доказано отсутствием специфических антител к аспирину у этих больных. В большинстве случаев диагноз основан на наличии в анамнезе реакции в виде симптомов назальной гиперреактивности после приема салицилатов и нестероидных противовоспалительныхсредств. Механизм этой реакции обусловлен возможной генетической предрасположенностью, а провоцирующими моментами могут быть синтетические салицилаты в виде пищевого тартразина в напитках, кондитерских и колбасных изделиях, некоторые натуральные продукты (малина, виноград).

У таких аспирин-чувствительных больных активизируется и приобретает определенную направленность метаболизм арахидоновой кислоты, образующейся из мембранных фосфолипидов тучных клеток, базофилов, эозинофилов и макрофагов. Результатом изменений метаболизма арахидоновой кислоты является накопление в тканях лейкотриенов, биологическая активность которых в сотни и тысячи раз превышает активность других медиаторов (простагландинов и гистамина). Лейкотриены вызывают 


\section{Рисунок 1. Диагностика назальной гиперреактивности}

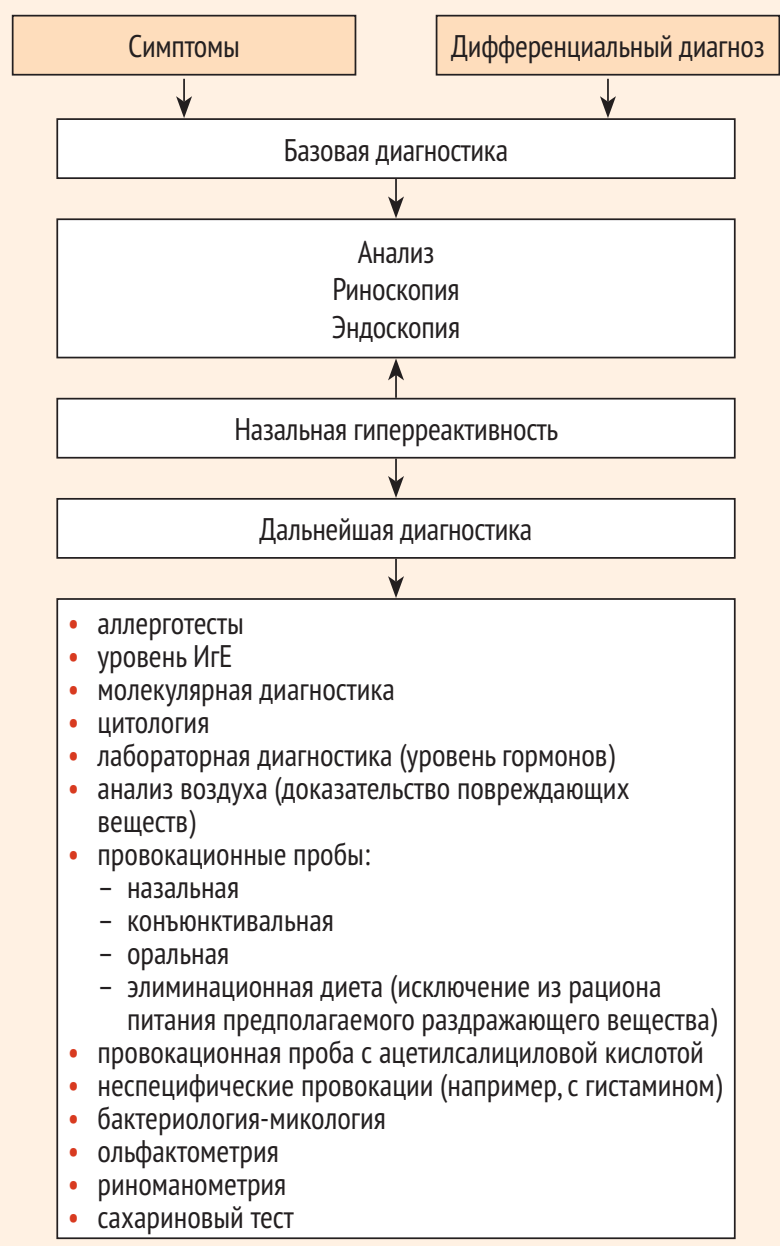

расширение сосудов, увеличивают сосудистую проницаемость, усиливают секрецию слизи, вызывают гиперергию чувствительных нервных окончаний, хемотаксис эозинофилов (в большей степени), базофилов и нейтрофилов в слизистую оболочку дыхательных путей.

Таким образом, механизмы назальной гиперреактивности очень разнообразны. Поэтому первостепенное значение для решения вопроса о назначении адекватного лечения (как медикаментозного, так и немедикаментозного) имеет дифференциальная диагностика причин назальной гиперреактивности.

Cимптоматика: рецидивирующая ринорея слизистого, прозрачного характера, затрудненное дыхание через нос, как правило, внезапно, после причин, которые указывает пациент: изменение температуры, изменение положения тела (чаще на спине), после приема алкоголя и т. д. Головная боль,

заложенность уха, слезотечение, снижение обоняния. Могут отмечаться болевые ощущения, которые сопровождаются гиперсимпатикотонией, повышением температуры.

Диагностика (рис. 1):

- анамнез,

- ЛОР-статус,

- эндоскопия полости носа и носоглотки,

- микробиологическое исследование мазка из полости Hoca,

- риноманометрия (до-и после использования сосудосуживающих капель),

исследование обоняния;

- провокационные тесты, единой методологии проверки реакции слизистой оболочки на различные стимулы не существует, используют: метахолин, гистамин, аденозин-5 монофосфат, холодный воздух, дистиллированную воду [8];

- рентгенологическое исследование околоносовых пазух носа (рис. 2).

В отдельных случаях необходимо дополнительно:

- ультразвуковое исследование;

- цитологическое исследование;

- биопсия (при наличии гранулем или опухоли);

- междисциплинарный консилиум (эндокринолог, пульмонолог).

Дифференциальная диагностика (рис. 3):

- инородное тело полости носа;

- атрезия хоан;

полипозный риносинусит;

- спонтанное дренирование кисты верхнечелюстной пазухи;

риноликворея;

- хронический синусит; гипертрофический ринит;

опухоль полости носа;

- специфические заболевания: сифилис, туберкулез, риносклерома, лепра.

- гранулематоз Вегенера;

опухоль носоглотки;

назальный цикл.

При постановке диагноза необхо-

Рисунок 2. Данные КТ полости носа и околоносовых пазух с визуализацией увеличенных в размере нижних носовых раковин, уменьшающих просвет полости носа

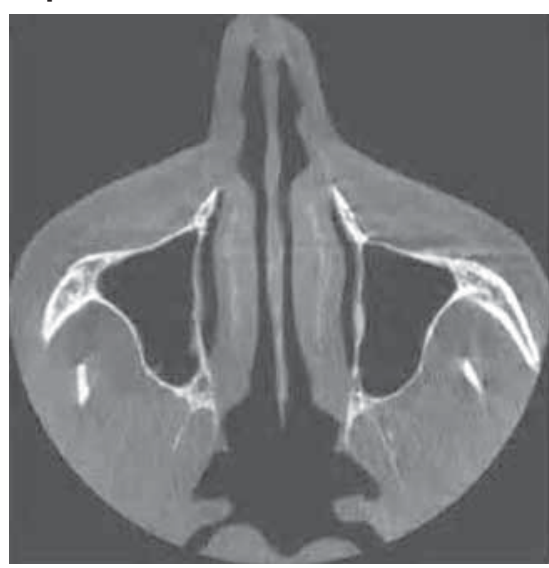
димо учитывать физиологический феномен, характеризующийся периодическим изменением резистентности слизистой оболочки поочередно правой и левой половины полости носа по отношению к потоку воздуха. Данное явление было впервые отмечено немецким врачом Рихардом Кайзером в 1895 г. Назальный цикл является необходимым условием хорошей работы мукоцилиарного эпителия и обеспечивается посменной работой венозных сплетений под воздействием вегетативной нервной системы. Благодаря чередованию фаз вазоконстрикции и вазодилатации регулируется объем вдыхаемого и выдыхаемого воздуха. Длительность одного периода колебаний у взрос- 
лых изменяется от 50 минут до 7,3 часа, у детей - от 15 минут до 3,5 часа.

\section{ВРАЧЕБНАЯ ТАКТИКА}

\section{Консервативная терапия:}

- элиминация раздражающего фактора (сигаретного дыма, алкоголя, отмена или замена лекарственного препарата, защитные мероприятия верхних дыхательных путей);

лечение основного заболевания;

- дыхательная гимнастика;

- физкультура, закаливание;

- аэроионотерапия.

Еще в древности люди замечали, что после дождя улучшается дыхание через нос. В античной Греции в IV в. до н. э. Гиппократ создавал специальные аэрарии. Американский ученый Бенджамин Франклин в начале XVIII в. использовал в лечебных целях статическое электричество. Чижевский А.Л. доказал, что отрицательные аэроионы в основном представлены кислородом, а положительные углекислым газом. Аэроионотерапия способствует улучшению носового дыхания;

- увлажнение слизистой оболочки растворами поваренной соли (физиологическим раствором), что особенно важно в условиях современного экологического стресса. Физраствор рекомендуется пациентам любого возраста в качестве ухода за полостью носа и при наличии проблем с затрудненным дыханием через нос и ринореей. Предназначен для увлажнения и очищения слизистой оболочки носа при сухости и раздражении во время простудных заболеваний, неблагоприятных условиях окружающей среды, а также для ежедневной гигиены полости носа: способствует поддержанию нормального физиологического состояния слизистой оболочки носа, разжижению слизи и облегчает ее удаление из носа, усиливает резистентность слизистой оболочки носа к болезнетворным бактериям и вирусам. Физиологический раствор помогает улучшить работу мукоцилиарного эпителия. При аллергическом рините способствует удалению аллергенов со слизистой оболочки носа. Использование препарата целесообразно у детей, страдающих вторичной гиперреактивностью слизистой оболочки на фоне гипертрофии аденоидов, аденоидита, при постинфекционном синдроме;

\section{Механизмы назальной гиперреактивности очень разнообразны. Поэтому первостепенное значение для решения вопроса о назначении адекватного лечения (как медикаментозного, так и немедикаментозного) имеет дифференциальная диагностика причин назальной гиперреактивности}

сосудосуживающие капли в нос при выраженном отеке слизистой оболочки и назальной обструкции (из-за опасности привыкания не более 6-10 дней);

- лекарственные препараты, образующие пленку на слизистой оболочке полости носа. Протеинат серебра помогает защитить мукоцилиарный эпителий, а также обладает антисептическим действием [9]. В педиатрической

\section{Рисунок 3. Дифференциальная диагностика гиперреактивных ринитов}

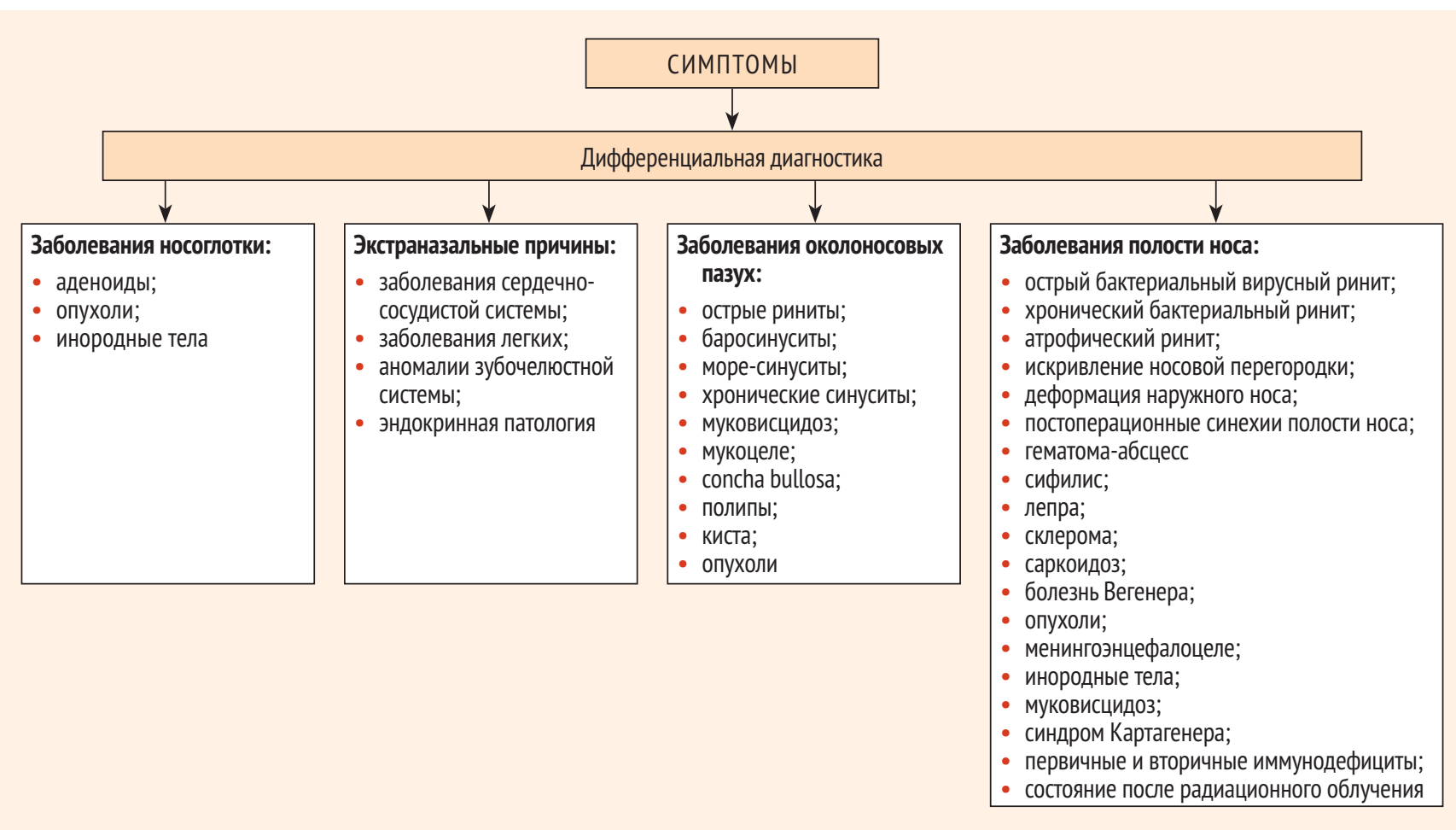




\section{Таблица 2. Лечение различных форм ринитов}

\begin{tabular}{|c|c|c|c|c|c|c|}
\hline Ринит & Аллергический & $\begin{array}{c}\text { Нервно- } \\
\text { рефлекторный }\end{array}$ & $\begin{array}{c}\text { Ирритотивно- } \\
\text { токсический }\end{array}$ & Эндокринный & $\begin{array}{c}\text { Пост- } \\
\text { инфекционный }\end{array}$ & Идиопатический \\
\hline Режим & ++ & +++ & + & +++ & & \\
\hline Динатриум-хромогликат - группа & ++ & & & & & + \\
\hline Системные стероиды & + & & & & & \\
\hline Местные стероиды & +++ & ++ & ++ & + & ++ & ++ \\
\hline Системные антигистамины & +++ & + & & & & + \\
\hline Местные антигистамины & ++ & & & & & + \\
\hline Ипратропия бромид & + & + & & & & + \\
\hline Гипосенсибилизация & ++ & & & & & \\
\hline Дезактивация & & + & & & & \\
\hline Хирургия & + & + & + & & & + \\
\hline Лечение основного заболевания & & & & ++ & & \\
\hline
\end{tabular}

Примечание: +++ - очень часто, ++ - часто, + - нечасто.

практике рекомендуем при отсутствии показаний к назначению антибактериальной терапии при постинфекционной гиперреактивности слизистой оболочки полости носа. Немаловажен длительный врачебный опыт использования протаргола в оториноларингологической практике с отсутствием побочных эффектов, поэтому препарат рекомендуем для детей и взрослых. Выпускается в форме капель и спрея. Самостоятельно готовится взрослым смешиванием таблетки с растворителем, и через 15 мин препарат готов к использованию.

В таблице 2 представлена схема терапевтических мероприятий при наиболее распространенных формах назальной гиперреактивности.

\section{Хирургическое лечение:}

Цель - нормализация нарушенных анатомических соотношений и улучшение вентиляции и дыхания через нос:

- септопластика;

- аденотомия;

- лечение заболеваний околоносовых пазух и глотки;

- использование щадящих методик, не нарушающих слизистой оболочки нижних носовых раковин (вазотомия, ультразвуковая или лазерная деструкция нижней носовой раковины). Целью данных методик является уменьшение объема раковины за счет замещения кавернозной ткани соединительной. На нижних носовых раковинах возможно проведение амбулаторных операций (иметь в виду риск кровотечения!);

другие операции в полости носа и околоносовых пазухах стационарно.

\section{Прогноз}

При установлении причины и ее устранении - благоприятный. В противном случае - персистирующий и рецидивирующий характер течения заболевания.

\section{ЗАКЛЮЧЕНИЕ}

Каждый век рождает свои проблемы, в том числе и в медицине. В последние годы все чаще и чаще произносятся слова «риносинусит» и «гиперреактивность». По прогнозам Всемирной организации здравоохранения, именно эти заболевания займут важное место в общей структуре заболеваемости в XXI в. Установление причины назальной гиперреактивности порой сложный и кропотливый процесс, в котором участвует пациент и врачи разных специальностей, так как от этого зависит выбор адекватной тактики лечения.

\section{ЛИТЕРАТУРА}

1. Segboer CL, Holland CT, Reinartz SM, Terreehorst I, Gevorgyan A, Hellings PW et al. Nasal hyper-reactivity is a common feature in both allergic and nonallergic rhinitis. Allergy, 2013, 68(11): 1427-34.

2. Wang ZY, Jiang MJ, Zhang Y, Cheng Y, Pang XJ, Xie YQ et al. Classification of non-allergic rhinitis based on inflammatory characteristics. Int J Clin Exp Med, 2015, 15(10): 17523-9.

3. Zenner H. Encyclopedia of Molecular Mechanisms of Disease. Berlin: Springer Verlag, 2009, pp 1432-1433.

4. Лопатин А.С. Ринит. М.: Литтера, 2010, 417 с.

5. Garrelds IM, de Graaf-in't Veld C, Gerth van Wijk R, Zijlstra FJ. Nasal hyperreactivity and inflammation in allergic rhinitis. Mediators Inflamm, 1996, 5(2): 79-94.

6. Shusterman D, Murphy MA. Nasal hyperreactivity in allergic and nonallergic rhinitis: a potential risk factor for non-specific building-related illness. Indoor Air, 2007, 4: 328-33.

7. Shusterman D. Nonallergic Rhinitis: Environmental Determinants. Immunol Allergy Clin North Am, 2016, 36(2): 379-99.

8. Lluch-Bernal M, Dordal MT, Antón E, Campo P, Colás C, Dávila I, et al. Nasal hyperreactivity: Nonspecific Nasal Provocation Tests. Review by the Rhinoconjunctivitis Committee of the Spanish Society of Allergy and Clinical Immunology. J Investig Allergol Clin Immunol, 2015, 25(6): 396-407.

9. Овчинников А.Ю., Мирошниченко Н.А., Шаграманян Г.Б., Рябинин В.А Роль местной терапии в лечении больных с острым риносинуситом в амбулаторных условиях. РМЖ, 2016, 21: 1407-1710. 